(C) 2015 IEEE. Personal use of this material is permitted. Permission from IEEE must be obtained for all other uses, in any current or future media, including reprinting/republishing this material for advertising or promotional purposes, creating new collective works, for resale or redistribution to servers or lists, or reuse of any copyrighted component of this work in other works. 


\title{
Study of the surface recombination velocity for ultraviolet and visible laser-fired contacts applied to silicon heterojunction solar cells
}

\author{
A. Morales-Vilches, C. Voz, M. Colina, D. Muñoz-Martin, I. Martín, P. Ortega, G. López, C. Molpeceres, \\ R. Alcubilla
}

\begin{abstract}
In this work we investigate the effect of the laser-firing process on the back surface passivation of p-type silicon heterojunction solar cells. For that purpose, two different nanosecond laser sources radiating at ultraviolet (355 nm) and visible (532 nm) wavelengths are employed. Firstly, we optimize the laser-firing process in terms of the electrical resistance of locally diffused point contacts. Specific contact resistance values as low as $0.91 \mathrm{~m} \Omega \cdot \mathrm{cm}^{2}$ and $0.57 \mathrm{~m} \Omega \cdot \mathrm{cm}^{2}$ are achieved for the visible and ultraviolet laser sources, respectively. In addition, the impact of the laser-firing process on the rear surface passivation is studied by analyzing the internal-quantum-efficiency curves of complete devices. Low surface recombination velocities in the range of $300 \mathrm{~cm} / \mathrm{s}$ are obtained for the ultraviolet laser with a $1 \%$ fraction of contacted area. This value increases to about $700 \mathrm{~cm} / \mathrm{s}$ for the visible laser, which indicates a significantly higher recombination at the contacted area. The best heterojunction solar cells with rear laser-fired contacts are obtained for the ultraviolet laser and reached a $17.5 \%$ conversion efficiency.
\end{abstract}

Index Terms- Heterojunction solar cells, Laser Firing Contact, Surface recombination velocity, passivation.

\section{INTRODUCTION}

In crystalline silicon (c-Si) solar cell technology, manufacturing costs are still dominated by the c-Si wafer price [1]. For that reason, the industry progressively use thinner substrates $(<200 \mu \mathrm{m})$ to reduce manufacturing costs [2]. Therefore, to avoid the bowing and eventual cracking of very thin wafers, the development of a complete low-temperature fabrication process is an attractive approach. In this scenario, the silicon heterojunction (SHJ) solar cell technology could be a suitable choice for the photovoltaic industry. The hydrogenated amorphous silicon (a-Si:H) layers involved in SHJ devices can be deposited at temperatures below $300{ }^{\circ} \mathrm{C}$, typically by Plasma Enhanced Chemical Vapor Deposition (PECVD) [3]. There are also good alternatives to obtain high quality transparent conductive oxide (TCO) layers and metallic electrodes at similarly low temperatures [4], [5]. Panasonic (formerly Sanyo) has excelled in this technology with its so-called HIT (Heterojunction with Intrinsic Thin layer) concept to achieve a highest conversion efficiency of $24.7 \%$ on n-type c-Si [6]. Attending to the band offsets at the a-Si:H/c-Si interface, n-type wafers would be fundamentally more suited to SHJ devices [7]. Nevertheless, conversion efficiencies above $21 \%$ have been also demonstrated on p-type wafers with a double-sided HIT structure [8].

An advantage of p-type wafers is the possibility to use an alternative structure which avoids the crosscontamination often observed when using both doping gases. This structure combines a dielectric passivation layer with a pattern of diffused aluminum $(\mathrm{Al})$ point contacts at the rear side. For instance, we have found that intrinsic hydrogenated amorphous silicon-carbon (a-SiC $: H$ ) layers can provide an excellent surface passivation on p-type c-Si substrates [9]. Furthermore, the implementation of point contact structures is now more viable owing to the fast development of the laser-firing technique [10]. Conversion efficiencies above 20\% have been already reported in conventional (diffused-emitter) solar cells incorporating rear laser-fired contacts (LFC) through different passivation layers [11]-[13]. Alternative metallic sources to produce laser-fired contacts have also been tested in completed devices [14], [15]. However, the variation of the wavelength of the laser used in this process has not been widely explored in heterojunction devices.

During the last years our group has been developing SHJ solar cells based on p-type wafers with a LFC solution on the rear side. To date, a highest $18 \%$ conversion efficiency has been reached on this fully lowtemperature fabrication process. In previous works, we reported the optimization of the process for a pulsed Nd-YAG laser source emitting at its fundamental wavelength (1064 nm) [16]. Although the laserfiring process is generally applied by means of an infrared (IR) laser, it has been reported that the

This work has been supported by the Spanish Ministry of Science and Innovation under projects ENE2013-48629-C4-1-R, TEC2011-26329 and IPT-420000-2010-6 (FEDER funded "Una manera de hacer Europa”) and by the European Commission (FP7, project HERCULES) under Grant agreement 60898.

A. M-V, C. V, I. M, P. O and R. A are with Universitat Politecnica de Catalunya (UPC), Departament d'Enginyeria Electronica, Grup de Recerca en Micro I Nanotecnologies. C/ Jordi Girona 1-3, Campus Nord, 08034 Barcelona, Spain. (Tel:+34934017488, email: anna.belen.morales@upc.edu).

M. C. was with UPC, Campus Nord, Barcelona. She is now with the Institut de Recerca en Energia de Catalunya, Barcelona, Spain.

D. M and C. M are with the Universidad Politecnica de Madrid, Departamento de Fisica Aplicada e Ingenieria de Materiales. 
particular laser source could significantly influence the quality of the contacts [17]. In this work we investigate the use of alternative visible (VIS) and ultraviolet (UV) laser sources emitting at $532 \mathrm{~nm}$ and $355 \mathrm{~nm}$, respectively. A comprehensive study will be presented considering not only the electrical quality of the contacts but also the rear surface recombination after the laser-firing process.

\section{EXPERIMENTAL}

\section{A. Device fabrication}

All the samples studied in this work were prepared on FZ quality $<100>$ oriented p-type $(0.5 \Omega \cdot \mathrm{cm}$ and $2.5 \Omega \cdot \mathrm{cm})$ c-Si wafers with a thickness of $280 \mu \mathrm{m}$. The process followed to fabricate complete SHJ solar cells with rear laser-fired contacts is described in Fig. 1. To begin with, a random pyramidal texture was obtained at the front surface as described elsewhere [18]. Subsequently, the substrates were cleaned by completing an RCA treatment and a short immersion in diluted (5\%) hydrofluoric acid (HF) [19]. Immediately afterwards, the wafers were loaded into a RF (13.56 MHz) direct PECVD system from Elettrorava S.p.A to deposit the heterojunction structure. First, the emitter consisted of a thin $(4 \mathrm{~nm})$ intrinsic a-SiC $\mathrm{x}: \mathrm{H}(\mathrm{x} \sim 0.2)$ buffer and an n-doped a-Si:H layer $(10 \mathrm{~nm})$. Following, on the rear side we deposited two a-SiC $\mathrm{x}: \mathrm{H}$ layers of different composition to obtain a good surface passivation and effective back reflectors. The first layer of $30 \mathrm{~nm}$ and a low carbon content $(\mathrm{x} \sim 0.2)$ provides excellent surface passivation. The stack is completed by a $70 \mathrm{~nm}$ thick carbon rich layer $(\mathrm{x} \sim 1)$ that serves as a back reflector. All these layers were deposited at a substrate temperature of $300{ }^{\circ} \mathrm{C}$. A detailed description of the deposition conditions was included in a previous work [20].

The following step in the fabrication of the device is the deposition of an indium-tin-oxide (ITO) front electrode. This layer was grown by RF (13.56 MHz) magnetron Sputtering from a sintered $\mathrm{In}_{2} \mathrm{O}_{3} / \mathrm{SnO}_{2}$ target (90/10 \%wt.) with a power density of $2.5 \mathrm{~mW} / \mathrm{cm}^{2}$. After depositing the ITO layer at room temperature, a soft annealing step at $160{ }^{\circ} \mathrm{C}$ was done for 1 hour in vacuum. In a previous work we showed that this step can significantly improve the quality of the emitter [21]. A photolithographic process and a wet etching of the ITO layer in diluted HF pattern the active area of the solar cells. The ndoped layer surrounding the defined active areas was dry-etched to isolate the fabricated solar cells. The front electrode is finished by evaporating a $2 \mu \mathrm{m}$ thick metallic contact, which consists in a $6 \%$ opaque silver grid thermally evaporated through a shadow mask.

For the back contact, a $1 \mu \mathrm{m}$ thick aluminium layer was evaporated on the rear side. Finally, point contacts were locally-diffused by applying a laser-firing process. In this work, two alternative nanosecond (ns) Q-switched laser sources have been investigated for the fabrication of LFC structures. The two lasers are from Spectra-Physics, an Explorer model emitting at a wavelength of $532 \mathrm{~nm}$ (VIS) and a Hippo model emitting at $355 \mathrm{~nm}$ (UV). Both of them are diode-pumped solid-state (DPSS) lasers based on neodymium-doped yttrium orthovanadate (Nd:YVO4) crystals. The lasers were operated at a fixed repetition frequency of $20 \mathrm{kHz}$ and regulated by means of an external energy attenuator. Only two pulses were required to form the point contacts for both laser sources. Concerning the optical set-up, a digital scanner HurryScan II 14 (Scanlab) was used with a $250 \mathrm{~mm}$ focal length for a $150 \mathrm{~mm} \times 150 \mathrm{~mm}$ working area.

\section{B. Characterization techniques}

The contactless Quasi-Steady-State Photoconductance (QSSPC) technique was used to evaluate the effective lifetime $\left(\tau_{e f f}\right)$ of device precursors at different steps of the fabrication process. A commercial Sinton WCT-120 apparatus was used for these measurements. The $\tau_{\text {eff }}$ value obtained by QSSPC accounts for all the recombination processes that take place in the device precursor:

$$
\frac{1}{\tau_{\text {eff }}}=\frac{1}{\tau_{b}}+\frac{S_{\text {front }}}{W}+\frac{S_{\text {rear }}}{W}
$$

The first term accounts for recombination in the bulk of the c-Si wafer. This recombination is characterized by a minority carrier lifetime $\left(\tau_{b}\right)$ that results from the Shockley-Read-Hall, Auger and band-to-band recombination. The second term in equation (1) corresponds to recombination in the emitter and at the space charge region of the junction. This term can be described by an effective front surface recombination velocity $\left(S_{\text {front }}\right)$ that is related to the emitter saturation current density. The last term gives the recombination at the rear surface, which can be described by an effective rear surface recombination velocity $\left(S_{\text {rear }}\right)$. In this work, we will particularly investigate the $S_{\text {rear }}$ values that result after different laser-firing processes. 


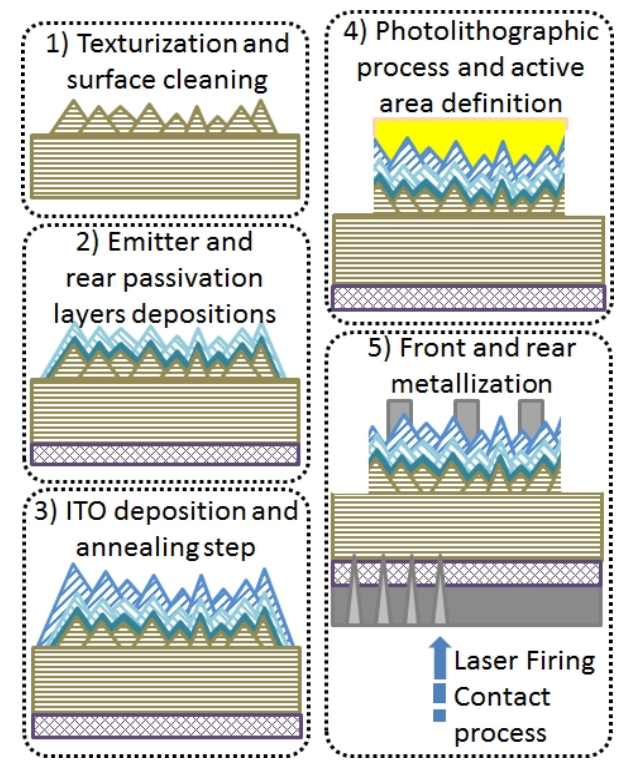

Fig. 1. Process sequence of the SHJ solar cell fabrication.

On complete devices, the current density-voltage (JV) characteristics were measured in dark and under standard AM1.5 illumination $\left(100 \mathrm{~mW} / \mathrm{cm}^{2}\right)$. Additionally, Quasi-Steady-State open-circuit voltage $\left(\mathrm{QSSV}_{\text {oc }}\right)$ measurements were done in order to calculate pseudo-JV curves without the effect of the series resistance. The $\mathrm{QSSV}_{\text {ос }}$ data were analysed to calculate also the effective lifetime after a complete fabrication process. In particular, an increase in the rear surface recombination induced by the laser-firing step could be evaluated by this method. The External-Quantum-Efficiency (EQE) curves of the fabricated solar cells were obtained by means of a QEX10 PV Measurements set-up. The EQE is defined as the ratio of collected charge carriers per photon incident to the solar cell. The reflectance spectra $(R)$ from the front side of the solar cells were measured by means of a UV-VIS-NIR Shimadzu 3600 spectrophotometer. These measurements allowed us to calculate the Internal-Quantum-Efficiency (IQE), which is the ratio of collected charge carriers per photon absorbed in the solar cell:

$$
\operatorname{IQE}(\lambda)=\frac{E Q E(\lambda)}{1-R(\lambda)}
$$

Finally, the behaviour of the IQE at long wavelengths was analyzed to estimate the effective diffusion length $\left(L_{\text {eff }}\right)$ of minority carriers for the fabricated solar cells [22].

\section{RESUlTS AND DISCUSSION}

\section{A. Optimization of laser-fired contacts}

As mentioned before, in this work we investigate VIS and UV laser sources to create laser-fired contacts as an alternative to the more usual IR option. The first step was an optimization of the laserfiring process in terms of the electrical resistance of the fabricated point contacts. Test samples were specifically prepared with a full-area ohmic contact on one side, while a passivation stack of a-SiC $: H$ layers was deposited on the opposite side. On the passivation stack, multiple isolated electrodes $(0.5 \times 0.5$ $\mathrm{cm}^{2}$ ) were formed by evaporating an Al layer through a shadow mask. Then, arrays of $3 \times 3$ point contacts separated a pitch $(p)$ of $1 \mathrm{~mm}$ were formed varying the laser operation conditions between different electrodes. Since the pitch was significantly longer than the wafer thickness $(W)$, the equivalent resistance for each electrode results from the parallel connection of 9 independent laser-fired contacts $\left(\mathcal{R}_{e q}=\right.$ $\left.\mathcal{R}_{L F C} / 9\right)$. The value of $\mathcal{R}_{L F C}$ is determined by the specific resistance of the point contact $\left(R_{c}\right)$ and the spreading resistance to the full-area reference contact at the opposite side:

$$
\mathcal{R}_{L F C}=\frac{R_{C}}{\pi r^{2}}+\frac{\rho}{2 \pi r} \operatorname{atan}\left(\frac{2 W}{r}\right) \approx \frac{R_{C}}{\pi r^{2}}+\frac{\rho}{4 r}
$$


where $r$ is the radius of the laser-fired contact and $\rho$ the resistivity of the substrate. The value of $R_{c}$ has to be minimized by optimizing the laser-firing process for the particular structure. In this work, the lowest $R_{c}$ values of $0.91 \mathrm{~m} \Omega \cdot \mathrm{cm}^{2}$ and $0.57 \mathrm{~m} \Omega \cdot \mathrm{cm}^{2}$ were obtained for the laser operation conditions summarized in Table I. Nevertheless, it is actually the net contribution of the base contact to the series resistance $\left(R_{S, b}\right)$ what will determine the quality of the point contact pattern. This value can be calculated as $R_{S, b}=$ $p^{2} \mathcal{R}_{L F C}$, which in terms of the fraction of contacted area $f=\pi r^{2} / p^{2}$ becomes:

$$
R_{S, b}=\frac{1}{f}\left(R_{c}+\frac{\pi}{4} \rho r\right)
$$

A low $f$ value of $0.9 \%$ with the $\mathrm{UV}$ laser was enough to obtain quite good $R_{S, b}$ values of only 0.28 $\Omega \cdot \mathrm{cm}^{2}$ and $0.11 \Omega \cdot \mathrm{cm}^{2}$ on $2.5 \Omega \cdot \mathrm{cm}$ and $0.5 \Omega \cdot \mathrm{cm}$ substrates, respectively. Similarly low values were obtained for the VIS laser with a $1 \%$ contacted area, $0.30 \Omega \cdot \mathrm{cm}^{2}$ and $0.13 \Omega \cdot \mathrm{cm}^{2}$ depending on the substrate resistivity.

TABLE I. PARAMETERIZATION OF THE LASER-FIRING PROCESS FOR THE VIS AND UV LASER SOURCES USED IN THIS WORK. ESTIMATION OF THE BASE CONTACT SERIES RESISTANCE FOR THE CONTACTED AREA FRACTIONS USED IN THE FABRICATION OF COMPLETE SOLAR CELLS.

\begin{tabular}{|c|c|c|c|c|c|c|c|c|}
\hline $\begin{array}{l}\text { Laser } \\
\text { source }\end{array}$ & $\begin{array}{l}\text { Pulse width } \\
\text { (ns) }\end{array}$ & $\begin{array}{l}\text { Power } \\
(\mathrm{mW})\end{array}$ & $\begin{array}{l}\text { Spot size } \\
(\varnothing=2 r)(\mu \mathrm{m})\end{array}$ & $\begin{array}{l}R_{C} \\
\left(\mathrm{~m} \Omega \cdot \mathrm{cm}^{2}\right) \\
\end{array}$ & $\begin{array}{l}\text { Pitch } \\
(\mu \mathrm{m})\end{array}$ & $\begin{array}{l}f \\
(\%)\end{array}$ & $\begin{array}{r}R_{S, b}( \\
\rho=2.5\end{array}$ & $\begin{array}{l}\left.\Omega \cdot \mathrm{cm}^{2}\right) \\
/ 0.5 \Omega \cdot \mathrm{cm}\end{array}$ \\
\hline $\begin{array}{l}\mathrm{UV} \\
355 \mathrm{~nm}\end{array}$ & 12 & 300 & 19 & 0.57 & 180 & 0.9 & 0.28 & 0.11 \\
\hline $\begin{array}{l}\text { VIS } \\
532 \mathrm{~nm}\end{array}$ & 15 & 180 & 23 & 0.91 & 200 & 1 & 0.30 & 0.13 \\
\hline
\end{tabular}

\section{B. Analysis of the effective lifetime}

The effective lifetime of the samples was monitored by QSSPC during the fabrication process. The $\tau_{\text {eff }}$ values measured in the device precursors after the ITO deposition and a soft annealing treatment are shown in Fig. 2. A very high effective lifetime of nearly $1 \mathrm{~ms}$ was obtained for $2.5 \Omega \cdot \mathrm{cm}$ substrates before the final metallization and laser-firing steps. This value was significantly lower $(\sim 0.27 \mathrm{~ms})$ for $0.5 \Omega \cdot \mathrm{cm}$ substrates, but bulk recombination could be already limiting the effective lifetime in these low resistivity wafers.

After the metallization and laser-firing steps, the fabricated solar cells were characterized by measuring their QSSV $_{\text {oc }}$ curves. This measurement is typically used to obtain pseudo J-V curves without the effect of the series resistance. However, QSSV $_{\text {oc }}$ data also implicitly contain information about the effective lifetime after a complete fabrication process [23].
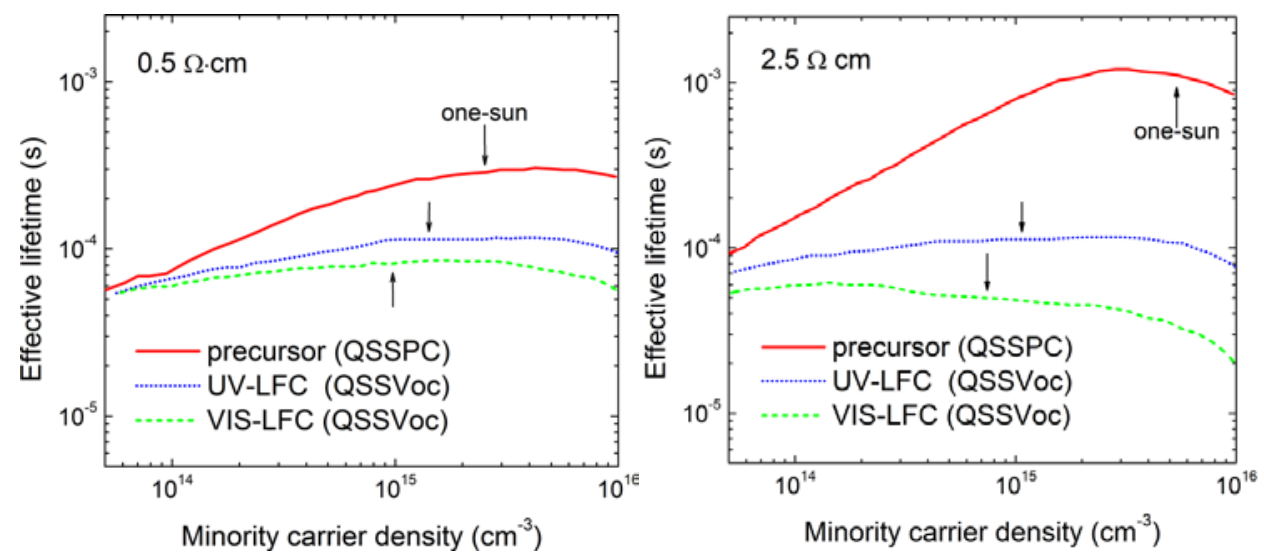

Fig. 2. Effective lifetime of device precursors compared to that of complete solar cells finished with VIS and UV laser-fired contacts at the rear side. This study was done on p-type c-Si wafers of resistivity $0.5 \Omega \cdot \mathrm{cm}$ and $2.5 \Omega \cdot \mathrm{cm}$. 
Conceptually, the $\tau_{\text {eff }}$ value could be estimated from:

$$
\tau_{\text {eff }} \approx \frac{\Delta n_{\text {avg }}}{G_{\text {net }}}
$$

where a uniform net generation rate $\left(G_{n e t}\right)$ is assumed and $\Delta n_{\text {avg }}$ is the average excess of minority carriers in the wafer. In good quality solar cells, we expect a nearly flat excess carrier density in open-circuit conditions. Thus, the $\Delta n_{\text {avg }}$ value of equation (5) could be approximated by the excess of minority carriers at the edge of the space charge region. This value can be calculated from the measured open-circuit voltage:

$$
n p \approx \Delta n\left(N_{A}+\Delta n\right)=n_{i}^{2} \exp \left(\frac{q V_{o c}}{k T}\right)
$$

that solved for $\Delta n$ leads to:

$$
\Delta n=\frac{\sqrt{N_{A}^{2}+4 n_{i}^{2} \exp \left(\frac{q V_{o c}}{k T}\right)}-N_{A}}{2}
$$

On the other hand, the value of $G_{\text {net }}$ can be closely approximated by:

$$
G_{n e t} \approx \frac{1}{q} \frac{J_{s c}}{W} I_{n e t}
$$

where $I_{\text {net }}$ is the illumination intensity measured in suns, which was measured by means of a calibrated photodetector installed in the QSSV $_{\text {ос }}$ set-up. The value of the short-circuit current density was independently obtained from the electrical characteristic of the solar cell under AM1.5 illumination. Finally, once $G_{n e t}$ and $\Delta n$ have been calculated, the $\tau_{\text {eff }}$ value of complete devices can be obtained as $\tau_{\text {eff }}$ $=\Delta n / G_{n e t}$ (Eq. 5). These curves are shown in figure 2 along with the effective lifetime of device precursors. An evident reduction in the effective lifetime of complete devices is observed, most likely related to an increase of the rear surface recombination after the laser-firing process. Nevertheless, relatively high $\tau_{\text {eff }}$ values in the range of $100 \mu$ sere still obtained for UV laser-fired contacts. Lower $\tau_{\text {eff }}$ values were obtained with the VIS laser source, especially on $2.5 \Omega \cdot \mathrm{cm}$ substrates. These results suggest a more gentle contact formation with the UV laser source. This possibility will be discussed later from the analysis of the electrical characteristics of these solar cells.

TABLE II. SUMMARY OF THE PARAMETERS EXTRACTED FOR THE ELECTRICAL CHARACTERIZATION OF COMPLETE DEVICES. THE

\begin{tabular}{|c|c|c|c|c|c|c|c|}
\hline \multicolumn{2}{|l|}{ Solar cells } & \multicolumn{2}{|c|}{$J V$ curves in the dark } & \multicolumn{4}{|c|}{$J V$ curves under AM1.5 } \\
\hline $\begin{array}{l}\text { Substrate } \\
\text { resistivity }\end{array}$ & Laser source & $\begin{array}{l}J_{o} \\
(\mathrm{pA} / \mathrm{cm} 2)\end{array}$ & $\begin{array}{l}R_{S} \\
\left(\Omega \cdot \mathrm{cm}^{2}\right)\end{array}$ & $\begin{array}{l}J_{s c} \\
\left(\mathrm{~mA} / \mathrm{cm}^{2}\right)\end{array}$ & $\begin{array}{l}V_{o c} \\
(\mathrm{mV})\end{array}$ & $\begin{array}{l}F F \\
(\%)\end{array}$ & $\begin{array}{l}\eta \\
(\%)\end{array}$ \\
\hline \multirow{2}{*}{$0.5 \Omega \cdot \mathrm{cm}$} & UV & 0.11 & 1.5 & 34.8 & 680 & 73.9 & 17.5 \\
\hline & VIS & 0.19 & 1.0 & 33.7 & 667 & 77.4 & 17.4 \\
\hline \multirow{2}{*}{$2.5 \Omega \cdot \mathrm{cm}$} & UV & 0.71 & 1.7 & 34.5 & 635 & 74.3 & 16.3 \\
\hline & VIS & 1.18 & 1.5 & 34.0 & 616 & 75.5 & 15.8 \\
\hline
\end{tabular}
DARK JV CURVES COULD BE FITTED BY CONSIDERING AN IDEAL DIODE WITH A SATURATION CURRENT DENSITY $J_{O}$ AND A SERIES RESISTANCE $R_{s}$. UNDER AM1.5 ILLUMINATION, THE JV CURVES ARE CHARACTERIZED BY THEIR STANDARD PHOTOVOLTAIC PARAMETERS $\left(J_{S C}, V_{O C}, F F\right.$ AND $\left.\eta\right)$.

\section{Electrical characteristics of complete solar cells}

The JV curves measured under illumination (AM1.5, $100 \mathrm{~mW} / \mathrm{cm} 2$ ) of the solar cells fabricated with UV laser-fired contacts are shown in Fig. 3 for the two substrate resistivities used in this work. The corresponding pseudo-JV curves deduced from QSSV $_{\text {ос }}$ measurements are also shown for comparison. These ideal curves, which are not affected by the series resistance, give information about the intrinsic quality of these structures. The insets in figure 3 show the corresponding dark JV and pseudo-JV curves of the fabricated solar cells. In the high injection regime, these could be described by a single-diode model with an ideality factor $\mathrm{n} \approx 1$ and a series resistance $\mathrm{R}_{\mathrm{S}}$. The values of $\mathrm{R}_{\mathrm{S}}$ were calculated by comparing the dark JV curve with its corresponding pseudo J-V characteristic. All the parameters extracted from these curves are summarized in Table II, together with the results obtained for the VIS 
laser source. Four identical devices were fabricated for each laser source and all of them showed very similar electrical characteristics. Besides, these experiments have been reproduced several times with rather good reliability.
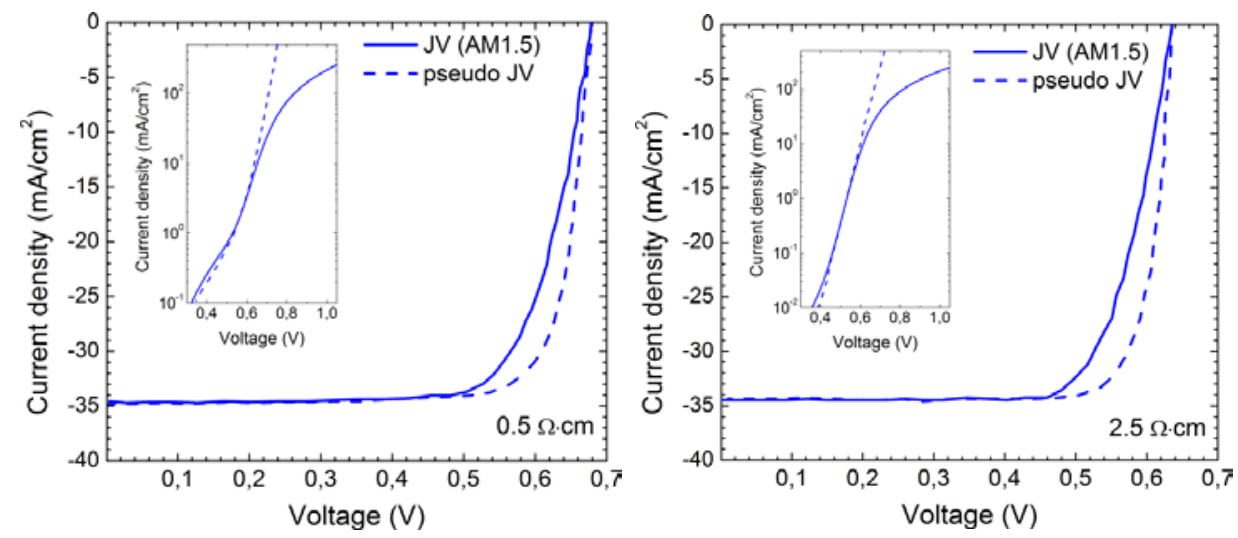

Fig. 3. Current-voltage characteristics measured under AM1.5 (100mW/cm2) illumination (solid lines) for the solar cells fabricated with UV laser-fired contacts on $0.5 \Omega \cdot \mathrm{cm}$ (left) and $2.5 \Omega \cdot \mathrm{cm}$ substrates (right). The pseudo-JV curves calculated from QSSVoc measurements (dashed lines) give the ideal behaviour eliminating the effect of the series resistance. The insets show the corresponding JV curves of these devices measured in the dark.

Regarding the parameters used to fit the dark JV curves, the $J_{o}$ values were clearly higher for the solar cells fabricated on $2.5 \Omega \cdot \mathrm{cm}$ wafers. This result suggests an important contribution of the base component, which depends on the doping level, to the total saturation current density of these devices. By comparing both laser sources, it was also clear that the solar cells with UV laser-fired contacts presented significantly lower $J_{o}$ values. This result could be related to a lower rear surface recombination velocity, as it was pointed before from the analysis of the effective lifetime curves (Fig. 2). The values of the total series resistance were rather moderate, but significantly higher than those calculated for the base contact in Table I. In this sense, less than a $10 \%$ of the total series resistance could be attributed to the rear electrode on $0.5 \Omega \cdot \mathrm{cm}$ substrates. This percentage increases to about a $20 \%$ for $2.5 \Omega \cdot \mathrm{cm}$ wafers because of a higher contribution of the spreading resistance. These results actually confirm the good electrical quality of the laser-fired contacts developed in this work. A further reduction of the series resistance could be accomplished by improving the front contact, either the ITO electrode or the metallic grid.

The parameters of the JV curves measured under AM1.5 illumination evidence that the best conversion efficiencies were obtained on $0.5 \Omega \cdot \mathrm{cm}$ substrates. This result was clearly related to the higher opencircuit voltage of these devices, in agreement with their lower $J_{o}$ values. Particularly, the solar cell with UV laser-fired contacts reached a remarkable $\mathrm{V}_{\text {oc }}$ value of $680 \mathrm{mV}$ and the highest conversion efficiency of $17.5 \%$. The $\mathrm{V}_{\text {ос }}$ and $\mathrm{J}_{\mathrm{sc}}$ values were lower for the solar cell fabricated using the VIS laser, probably due to a higher rear surface recombination velocity. Only the fill factor was better in this device that finally reached a $17.4 \%$ conversion efficiency. Since the $R_{S}$ values were very similar for both laser sources, the FF value could be influenced by unintentional shunts at the front electrode. In this regard, the slight variations in both the $R_{s}$ and FF values could be explained by the front contact rather than by the particular laser-firing step.

A very similar trend was observed for $2.5 \Omega \cdot \mathrm{cm}$ substrates, with a higher $\mathrm{V}_{\text {ос }}$ of $635 \mathrm{mV}$ again for the UV laser. These devices were also characterized by $\mathrm{QSSV}_{\text {ос }}$ and these curves have been used in the previous section to estimate the $\tau_{\text {eff }}$ value of minority carriers after a complete fabrication process. The QSSV $_{\text {ос }}$ measurements also allow calculating pseudo-JV curves that are not affected by the series resistance of the solar cells. These pseudo-JV curves shown in Fig. 3 (dashed lines) would give conversion efficiencies up to $19 \%$ and $18 \%$ on $0.5 \Omega \cdot \mathrm{cm}$ and $2.5 \Omega \cdot \mathrm{cm}$ wafers, respectively.

\section{Rear surface recombination velocity}

The electrical characteristics of the solar cells suggest that the rear surface passivation was preserved significantly better by the UV laser source compared to the VIS one. Also the $\tau_{\text {eff }}$ curves calculated from $\mathrm{QSSV}_{\text {ос }}$ data point in the same direction. Nevertheless, these measurements actually give information about the whole device structure and could be affected by multiple factors during a complete fabrication process. Thus, a direct estimation of the effective rear surface recombination velocity $\left(S_{\text {rear }}\right)$ was necessary for a more confident comparison of both laser-firing steps. In this sense, very valuable 
information on the rear surface passivation could be obtained by analysing the IQE curves of the solar cells at long wavelengths.
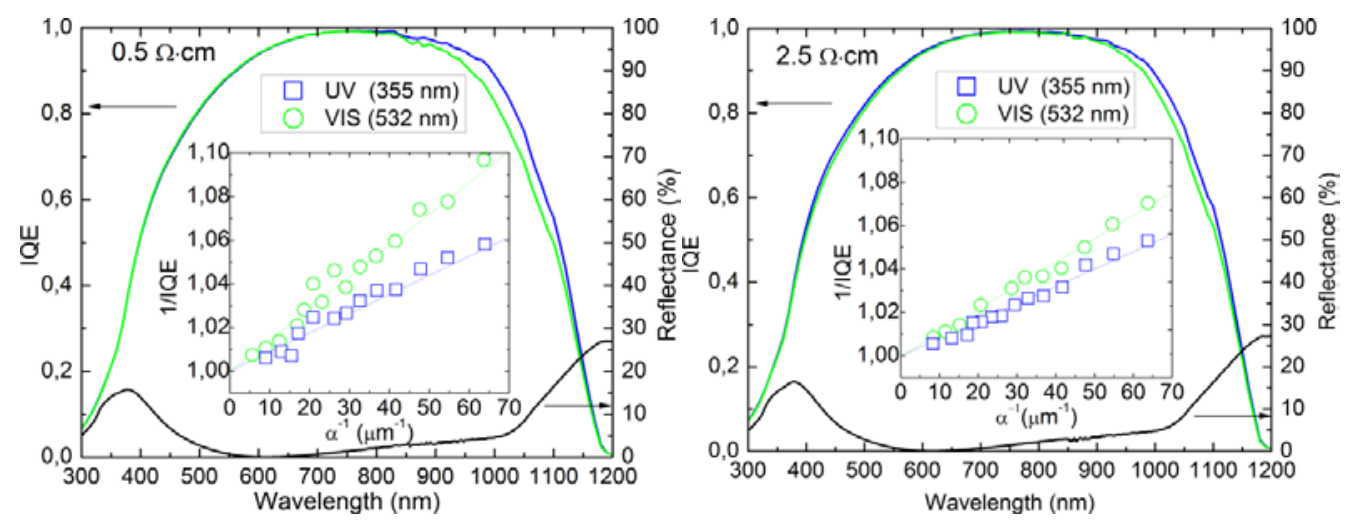

Fig. 4. IQE curves and reflectance spectra of the solar cells with UV and VIS laser-fired contacts on $0.5 \Omega \cdot \mathrm{cm}$ (left) and $2.5 \Omega \cdot \mathrm{cm}$ (right) wafers. The insets show the inverse of the IQE vs. the penetration depth (inverse of the absorption coefficient) in the wavelength range from $850 \mathrm{~nm}$ to $900 \mathrm{~nm}$.

Fig. 4 compares the IQE curves of the solar cells fabricated with both laser sources. The main observation is an improvement of the IQE at long wavelengths in the case of UV laser-fired contacts. In the insets, the inverse of the IQE is plotted versus the inverse of the absorption coefficient $(\alpha)$ for the wavelength range between $800 \mathrm{~nm}$ and $950 \mathrm{~nm}$. As seen in equation 9 , the reciprocal slope of a linear fit to this plot can be used to calculate the effective diffusion length $\left(L_{e f f}\right)$ of minority carriers in the c-Si wafer [22]. The angle $\theta=41.8^{\circ}$ is given by the refraction of the incident light on the chemically textured surface of (100)-oriented silicon wafers.

$$
\frac{1}{I Q E}=1+\frac{\cos (\theta)}{L_{e f f}} \alpha^{-1}
$$

TABLE III. SUMMARY OF THE EFFECTIVE DIFFUSION LENGTH $\left(L_{\text {EFF }}\right)$ AND REAR SURFACE RECOMBINATION VELOCITY $\left(S_{\text {REAR }}\right)$ FOR THE SOLAR CELLS STUDIED IN THIS WORK. THESE VALUES CONFIRM THAT THE UV LASER WAS ABLE TO PRESERVE BETTER THE REAR SURFACE PASSIVATION DURING THE LASER-FIRING PROCESS.

\begin{tabular}{llll}
\hline \hline $\begin{array}{l}\text { Samples } \\
\text { Substrate resistivity }\end{array}$ & Laser-source & $L_{\text {eff }}(\mu \mathrm{m})$ & $S_{\text {rear }}(\mathrm{cm} / \mathrm{s})$ \\
\hline \hline \multirow{2}{*}{$2.5 \Omega \cdot \mathrm{cm}$} & UV & 924 & 472 \\
& VIS & 686 & 752 \\
\hline \multirow{2}{*}{$0.5 \Omega \cdot \mathrm{cm}$} & UV & 842 & 358 \\
& VIS & 514 & 900 \\
\hline \hline
\end{tabular}

The $L_{\text {eff }}$ values obtained from these fittings are summarized in Table III. These values clearly exceeded the wafer thickness $(W=280 \mu \mathrm{m})$ in all cases, but the best results were definitely obtained for rear contacts processed with the UV laser source $\left(L_{\text {eff }} / W>3\right)$. Additionally, these $L_{\text {eff }}$ values could be used to estimate the effective surface recombination velocity at the rear side of the solar cells [24]:

$$
S_{\text {rear }}=\frac{D_{b}}{L_{b}} \times \frac{L_{b}-L_{e f f} \cdot \tanh \left(\frac{W}{L_{b}}\right)}{L_{e f f}-L_{b} \cdot \tanh \left(\frac{W}{L_{b}}\right)}
$$

where $D_{b}$ is the diffusion coefficient of minority carriers (electrons) in the base of the solar cell (p-type substrate). The bulk diffusion length in equation (9) is given by $L_{b}=\sqrt{D_{b} \tau_{b}}$, where $\tau_{b}$ is the bulk lifetime of minority carriers in the c-Si wafer. The value of $D_{b}$ depends on the doping concentration and, at room temperature, it can be considered $30.6 \mathrm{~cm}^{2} / \mathrm{s}$ for $2.5 \Omega \cdot \mathrm{cm}$ and $23.2 \mathrm{~cm}^{2} / \mathrm{s}$ for $0.5 \Omega \cdot \mathrm{cm}$ substrates. For the high quality FZ wafers used in this work, the bulk lifetime is only limited by intrinsic recombination (Auger and band-to-band) in the c-Si substrate. Then, very long $\tau_{b}$ values of about $14 \mathrm{~ms}(2.5 \Omega \cdot \mathrm{cm}) \mathrm{and}$ $0.8 \mathrm{~ms}(0.5 \Omega \cdot \mathrm{cm})$ can be estimated for each substrate resistivity [25]. The $S_{\text {rear }}$ values calculated using equation (10) are summarized in Table III, where it is finally confirmed the superior quality of the UV laser-firing process. Good $S_{\text {rear }}$ values of only $300-500 \mathrm{~cm} / \mathrm{s}$ were obtained for the UV laser source, while 
these values were approximately doubled when the contacts were made with the VIS laser. The $S_{\text {rear }}$ value can be interpreted as the effective surface recombination that results from the initially well passivated rear surface and the much higher recombination velocity at the laser-fired contacts [11]. Note that the fraction of contacted area was rather low and very similar for both laser sources $(f \approx 1 \%)$. Thus, the lower $S_{\text {rear }}$ values could only be explained by considering laser-fired contacts of significantly better quality for the UV laser source.

\section{CONCLUSION}

The laser-firing process has been optimized for nanosecond VIS (532 nm) and UV (355 nm) laser sources alternative to the more usual IR choice. Excellent specific contact resistances as low as 0.91 $\mathrm{m} \Omega \cdot \mathrm{cm}^{2}$ (VIS) and $0.57 \mathrm{~m} \Omega \cdot \mathrm{cm}^{2}$ (UV) were obtained depending on the wavelength of the laser source.

These results evidence the flexibility of the laser-firing process to be adapted to different technological requirements. For instance, shorter wavelengths could be more suited to the production of laser-fired contacts on very thin wafers. Particularly, in this work we have evaluated the laser-firing process on ptype SHJ solar cells with an intrinsic rear passivation stack of a-SiC $\mathrm{x}: \mathrm{H}$ layers. A fraction of contacted area of about $1 \%$ was enough to obtain patterns of laser-fired contacts with a very small contribution (10$20 \%)$ to the total series resistance of the solar cell.

Although in terms of the contact resistance similar results were obtained for both laser sources, the solar cells fabricated with UV laser-fired contacts performed significantly better. A detailed analysis of the IQE curves confirm a significantly lower rear surface recombination velocity $\left(S_{\text {rear }}=300-500 \mathrm{~cm} / \mathrm{s}\right.$ ) for the UV laser source. The best solar cell, which was fabricated with UV laser-fired contacts on a 0.5 $\Omega \cdot \mathrm{cm}$ wafer, reached a $17.5 \%$ conversion efficiency with a remarkable $\mathrm{V}_{\text {oc }}$ of $680 \mathrm{mV}$.

The suspected mechanism behind the better performance of the UV laser-fired contacts might be that the heating induced by that laser source is less extended into the absorber compared to the VIS laser. Thus, fewer defects would be generated in the absorber and also a higher concentration of $\mathrm{Al}$ atoms would be expected at the locally diffused BSF contact. According to pseudo-JV curves deduced from QSSV $_{\text {oc }}$ data, this efficiency could be significantly increased by reducing the series resistance of the device. The $\mathrm{R}_{\mathrm{S}}$ value is clearly limited by the front electrode, which gives an indication of the high quality of the laser-fired contacts developed in this work.

\section{REFERENCES}

[1] S. A. Mann, M. J. de Wild-Scholten, V. M. Fthenakis, W. G. J. H. M. van Sark, and W. C. Sinke, "The energy payback time of advanced crystalline silicon PV modules in 2020: a prospective study,” Prog. Photovoltaics Res. Appl., vol. 22, no. 11, pp. 1180-1194, Nov. 2014.

[2] F. Dross, K. Baert, T. Bearda, J. Deckers, V. Depauw, O. El Daif, I. Gordon, A. Gougam, J. Govaerts, S. Granata, R. Labie, X. Loozen, R. Martini, A. Masolin, B. O’Sullivan, Y. Qiu, J. Vaes, D. Van Gestel, J. Van Hoeymissen, A. Vanleenhove, K. Van Nieuwenhuysen, S. Venkatachalam, M. Meuris, and J. Poortmans, "Crystalline thin-foil silicon solar cells: where crystalline quality meets thin-film processing,” Prog. Photovoltaics Res. Appl., vol. 20, no. 6, pp. 770-784, Sep. 2012.

[3] U. K. Das, M. Z. Burrows, M. Lu, S. Bowden, and R. W. Birkmire, "Surface passivation and heterojunction cells on Si (100) and (111) wafers using dc and rf plasma deposited Si:H thin films,” Appl. Phys. Lett., vol. 92, no. 6, p. 063504, 2008.

[4] D. Zhang, a. Tavakoliyaraki, Y. Wu, R. a. C. M. M. van Swaaij, and M. Zeman, "Influence of ITO deposition and post annealing on HIT solar cell structures,” Energy Procedia, vol. 8, no. April, pp. 207-213, Jan. 2011.

[5] H. Jiang, W. Shi, a. Shaikh, and E. Graddy, “Advanced screen printed polymer Ag paste for HIT cells,” 2011 37th IEEE Photovolt. Spec. Conf., pp. 001456-001457, Jun. 2011.

[6] M. Taguchi, A. Yano, S. Tohoda, K. Matsuyama, Y. Nakamura, T. Nishiwaki, K. Fujita, and E. Maruyama, “24.7\% Record Efficiency HIT Solar Cell on Thin Silicon Wafer,” IEEE J. Photovoltaics, vol. 4, no. 1, pp. 9699, Jan. 2014.

[7] L. Korte and M. Schmidt, "Doping type and thickness dependence of band offsets at the amorphous/crystalline silicon heterojunction,” J. Appl. Phys., vol. 109, no. 6, p. 063714, Mar. 2011.

[8] A. Descoeudres, Z. C. Holman, L. Barraud, S. Morel, S. De Wolf, and C. Ballif, ">21\% Efficient Silicon Heterojunction Solar Cells on n- and p-Type Wafers Compared,” IEEE J. Photovoltaics, vol. 3, no. 1, pp. 83-89, Jan. 2013.

[9] I. Martín, M. Vetter, M. Garín, A. Orpella, C. Voz, J. Puigdollers, and R. Alcubilla, “Crystalline silicon surface passivation with amorphous SiCx:H films deposited by plasma-enhanced chemical-vapor deposition,” J. Appl. Phys., vol. 98, no. 11, p. 114912, Dec. 2005. 
[10] E. Schneiderlöchner, R. Preu, R. Lüdemann, and S. W. Glunz, "Laser-fired rear contacts for crystalline silicon solar cells,” Prog. Photovoltaics Res. Appl., vol. 10, no. 1, pp. 29-34, Jan. 2002.

[11] W. Brendle, V. X. Nguyen, A. Grohe, E. Schneiderlöchner, U. Rau, G. Palfinger, and J. H. Werner, “20·5\% efficient silicon solar cell with a low temperature rear side process using laser-fired contacts,” Prog. Photovoltaics Res. Appl., vol. 14, no. 7, pp. 653-662, Nov. 2006.

[12] P. Ortega, I. Martín, G. Lopez, M. Colina, A. Orpella, C. Voz, and R. Alcubilla, "p-type c-Si solar cells based on rear side laser processing of Al2O3/SiCx stacks,” Sol. Energy Mater. Sol. Cells, vol. 106, pp. 80-83, Nov. 2012.

[13] D. Suwito, S. Janz, M. Hermle, and S. W. Glunz, "HIGH-EFFICIENCY SILCON SOLAR CELLS WITH INTRINSIC AND DOPED A-SiCx REAR SIDE PASSIVATION,” in 24th European PV Solar Energy Conference and Exhibition, 2009.

[14] M. Hofmann, D. Erath, B. Bitnar, L. Gautero, J. Nekarda, A. Grohe, D. Biro, J. Rentsch, and R. Preu, “Industrial type CZ silicon solar cells with screen-printed fine line front contacts and passivated rear contacted by Laser Firing,” Proc. 23rd EU PVSEC, pp. 1704-1707, 2008.

[15] J. Nekarda, M. Graf, A. Rodofili, R. Preu, R. Böhme, and D. Sontag, "Laser-based foil metallization for industrical PERC solar cells,” Proc. 28th EU PVSEC, pp. 797-799, 2014

[16] A. Morales-Vilches, C. Voz, M. Colina, G. Lopez, I. Martin, A. Orpella, J. Puigdollers, M. Garcia, and R. Alcubilla, "Progress in silicon heterojunction solar cell fabrication with rear laser-fired contacts," in 2013 Spanish Conference on Electron Devices, 2013, pp. 345-348.

[17] C. Molpeceres, M. I. Sánchez, M. Morales, D. Muñoz-Martín, S. Lauzurica, I. Martín, P. Ortega, M. Colina, C. Voz, and R. Alcubilla, "Parameterization of local laser doping and laser-fired contacts for high efficiency c-Si solar cells,” Phys. Procedia, vol. 39, pp. 693-701, Jan. 2012.

[18] P. Papet, O. Nichiporuk, A. Kaminski, Y. Rozier, J. Kraiem, J.-F. Lelievre, A. Chaumartin, A. Fave, and M. Lemiti, "Pyramidal texturing of silicon solar cell with TMAH chemical anisotropic etching," Sol. Energy Mater. Sol. Cells, vol. 90, no. 15, pp. 2319-2328, Sep. 2006.

[19] W. Kern and D. A. Puotinen, "Cleaning solution based on hydrogen peroxide for use in silicon semiconductor technology,” RCA Rev., vol. 31, pp. 187-206, 1970.

[20] A. Morales, C. Voz, M. Colina, G. López, I. Martín, A. Orpella, J. Puigdollers, M. García, and R. Alcubilla, "Progress in Silicon Heterojunction Solar Cell fabrication with rear laser-fired contacts,” IEE Explor., vol. 120000, pp. 345-348, 2012.

[21] A. Morales-Vilches, C. Voz, M. Colina, G. López, I. Martín, P. Ortega, A. Orpella, and R. Alcubilla, "Recovery of Indium-tin-oxide/silicon Heterojunction Solar Cells by Thermal Annealing,” Energy Procedia, vol. 44, pp. 39, 2014.

[22] P. A. Basore, "Extended spectral analysis of internal quantum efficiency," in Conference Record of the Twenty Third IEEE Photovoltaic Specialists Conference - 1993 (Cat. No.93CH3283-9), 1993, pp. 147-152.

[23] M. J. Kerr, A. Cuevas, and R. A. Sinton, "Generalized analysis of quasi-steady-state and transient decay open circuit voltage measurements,” J. Appl. Phys., vol. 91, no. 1, p. 399, Jan. 2002.

[24] M. Spiegel, B. Fischer, S. Keller, and E. Bucher, "Separation of bulk diffusion length and back surface recombination velocity by improved IQE-analysis," in Conference Record of the Twenty-Eighth IEEE Photovoltaic Specialists Conference - 2000 (Cat. No.00CH37036), 2000, pp. 311-314.

[25] M. J. Kerr and A. Cuevas, “General parameterization of Auger recombination in crystalline silicon,” J. Appl. Phys., vol. 91, no. 4, p. 2473, Feb. 2002. 